\title{
Girls' Education Roadmap: 2021 Report Summary
}

\author{
Stephanie Psaki \\ Population Council \\ Nicole Haberland \\ Population Council \\ Meredith L. Kozak \\ Population Council \\ Lauren Woyczynski \\ Population Council
}

Follow this and additional works at: https://knowledgecommons.popcouncil.org/departments_sbsr-pgy

Part of the Gender Equity in Education Commons

How does access to this work benefit you? Let us know!

\section{Recommended Citation}

Psaki, Stephanie, Nicole Haberland, Meredith L. Kozak, and Lauren Woyczynski. 2021. "Girls' Education Roadmap: 2021 Report Summary," EGER Reports. New York: Population Council. 


\section{Key Takeaways}
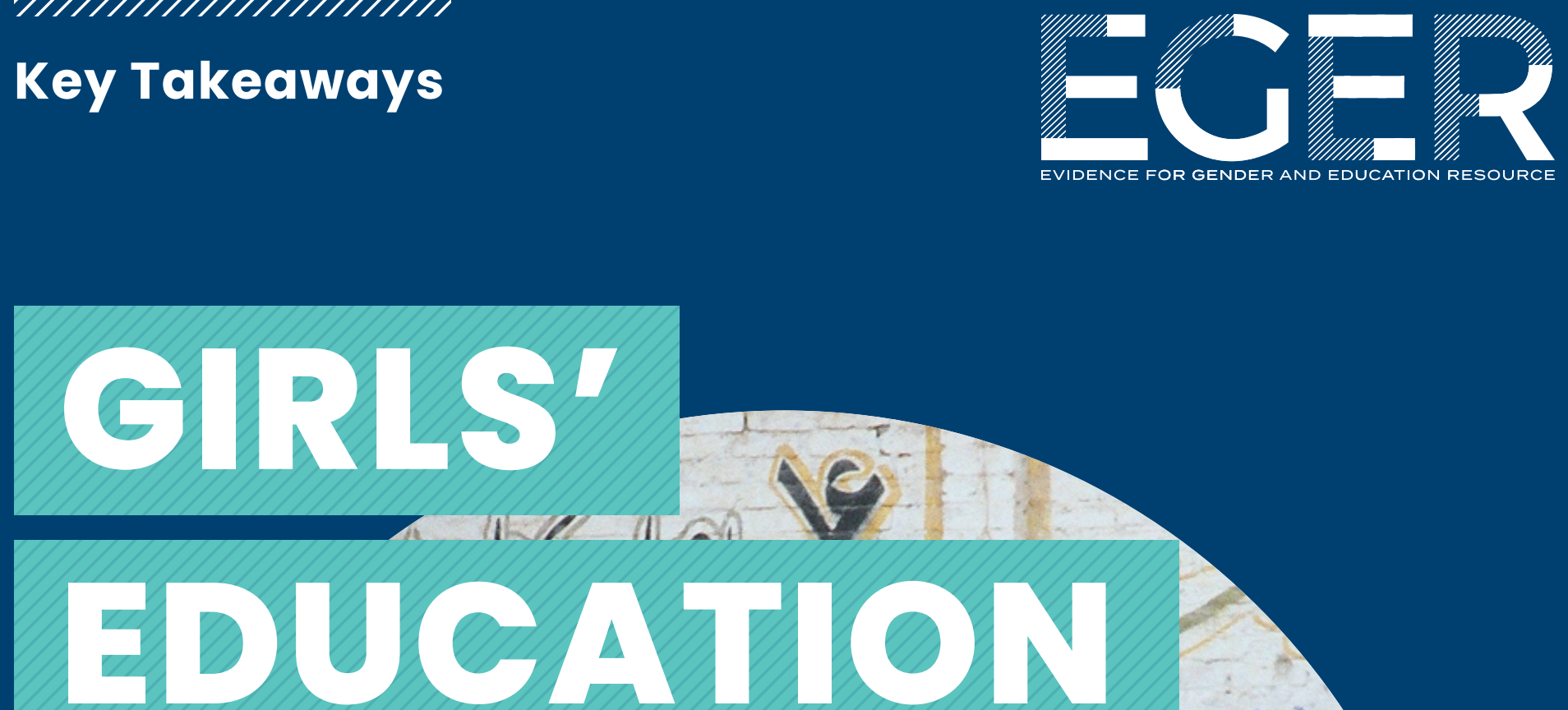

$-6-1-1$ iा ra
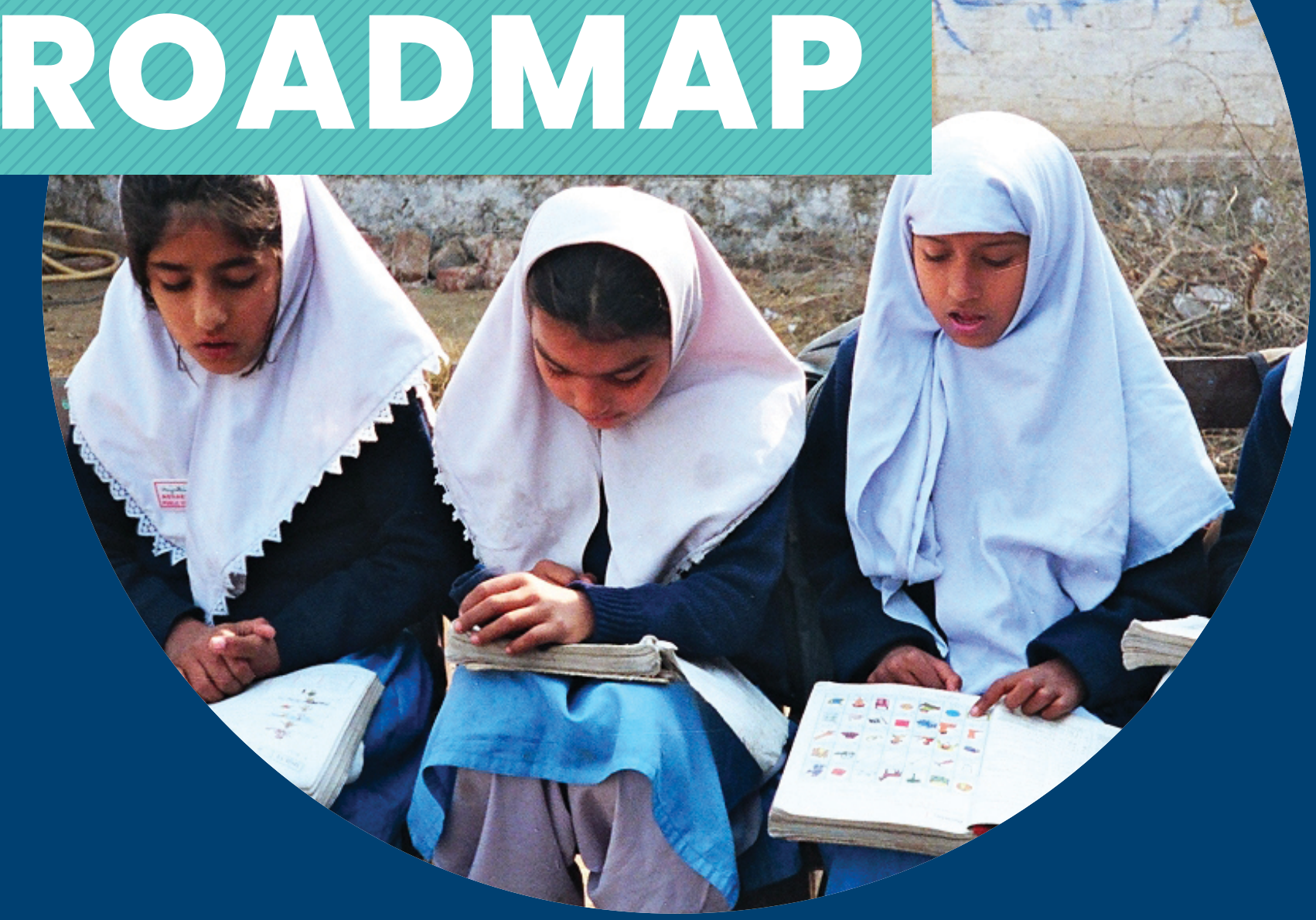


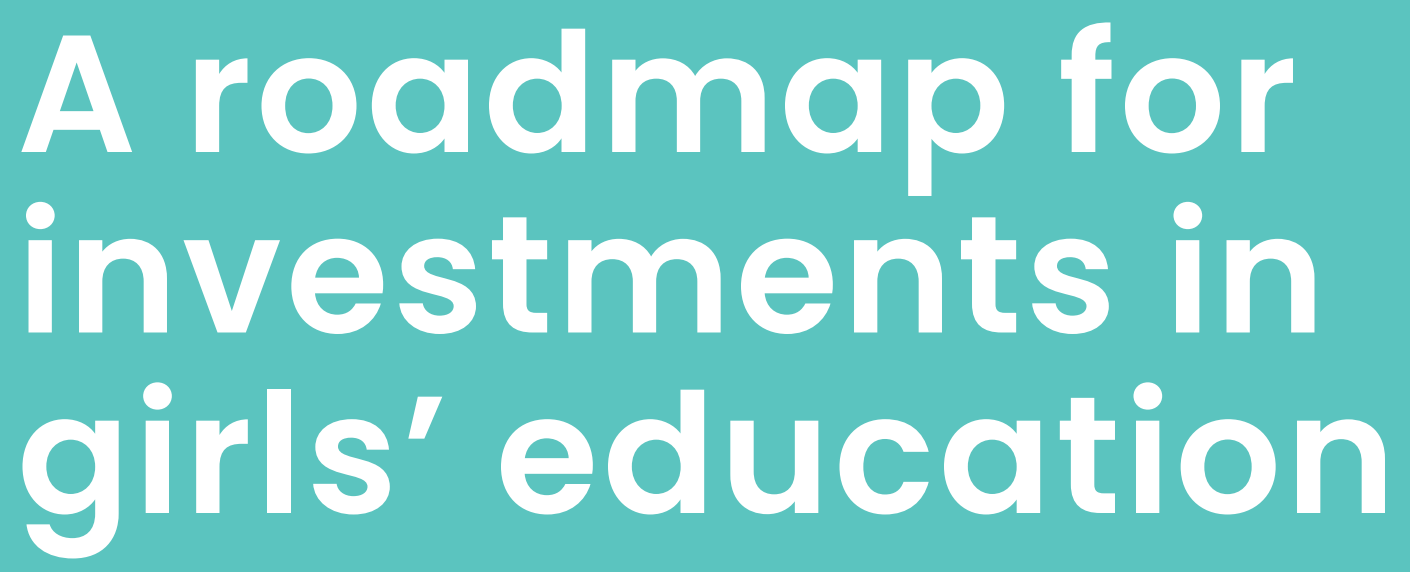

Prior to the COVID-19 pandemic, millions of young people, especially girls, were out of school. We faced a global learning crisis, with widespread illiteracy and innumeracy, even among those attending primary school.

The world has changed dramatically over the last year, deepening existing inequalities, and creating even more uncertainty about the way forward in global girls' education. Against this backdrop of shrinking economies and growing needs, the question of how we will invest valuable resources is more pressing than ever.

While insufficient to meet the vast needs, billions of dollars are being invested in girls' education advocacy, program, and policy solutions around the world. At the same time, hundreds of millions are invested in research about what works in education. And yet, the policies and approaches that are pursued often don't line up with what researchers find is effective.

The result is that governments, international organizations, and NGOs are too often investing scarce resources in policies or interventions without knowing whether they work. Researchers are too often testing interventions they find interesting, rather than asking whether the most common approaches in the field are delivering results. And donors and policymakers are left scratching their heads wondering where to invest.
That's where the Girls' Education Roadmap comes in. In a first-of-its-kind report, we reviewed thousands of studies and assessed hundreds of organizations working across dozens of countries to figure out who's doing what, what's working where, and what are the biggest needs facing girls.

OUR GOALS ARE SIMPLE: to make sure governments, NGOs, and donors are investing in what works and to make sure researchers are focusing on answering the most urgent and important questions for the field. 


\section{How can we better align needs, evidence, and practice in girls' education?}

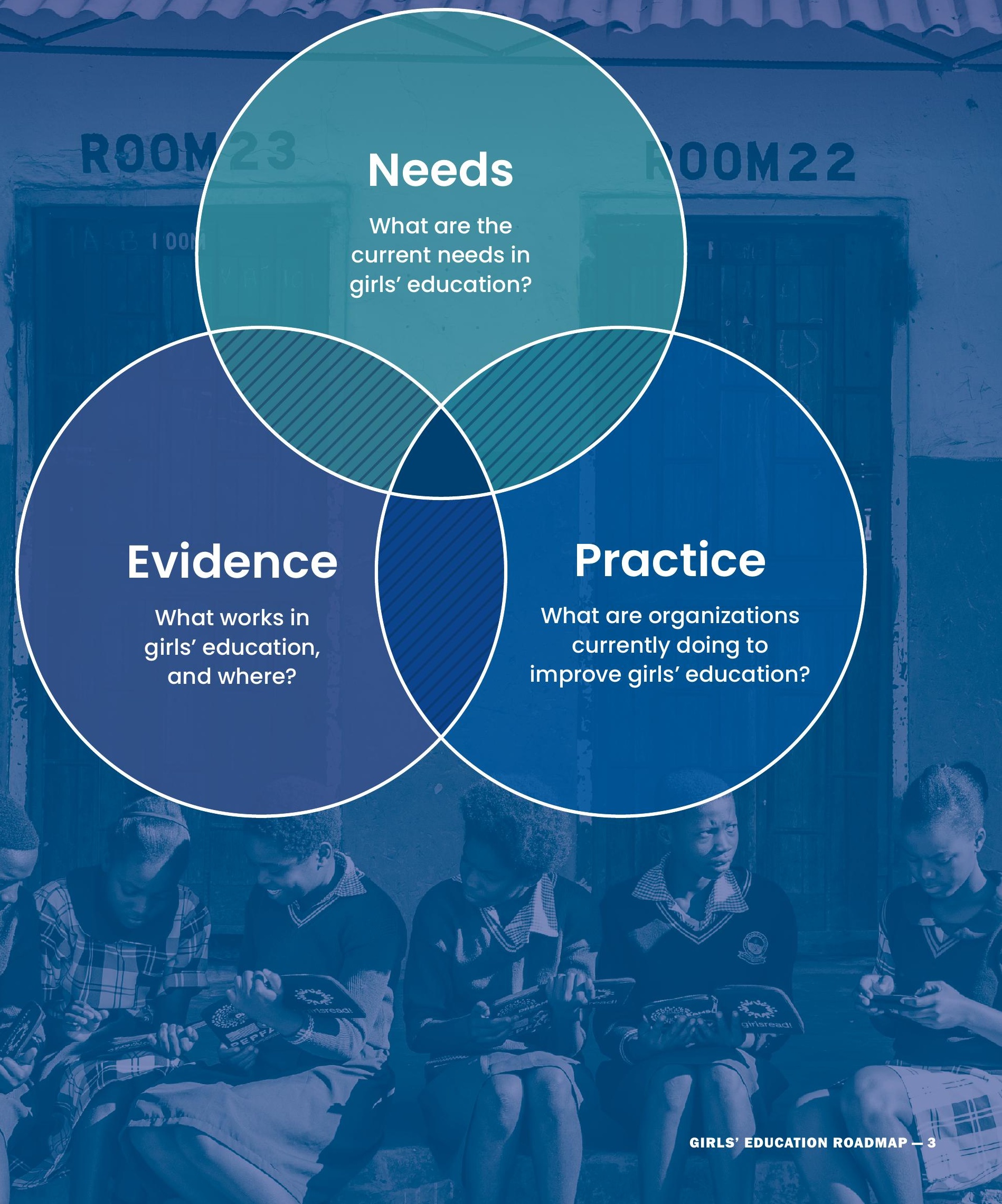




\section{Investments that will make the biggest difference for girls' education}

The most effective interventions will depend on the particular challenges facing girls and their families in each setting. Understanding those challenges-and tailoring our responses effectively-will be key to success.

\section{Programs or policies that work to improve school enrollment and enhance educational attainment for girls:}

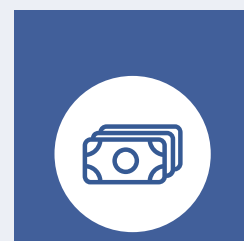

Addressing the cost of schooling

(e.g. through conditional cash

transfers, scholarships, provision

of school materials/uniforms)
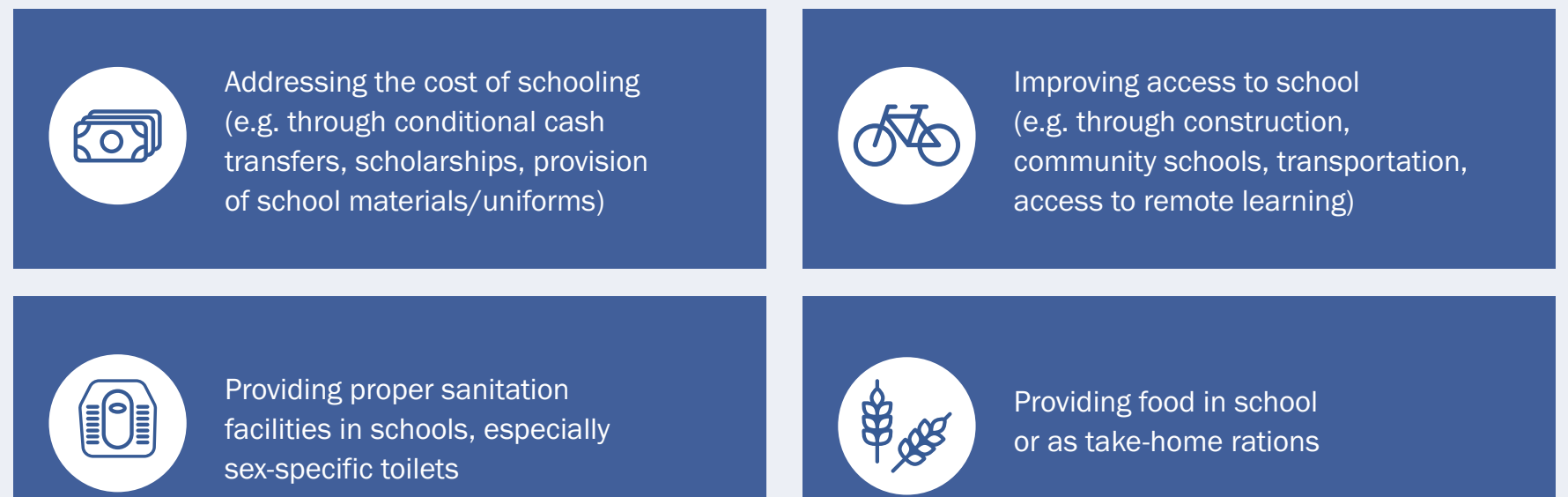

Providing proper sanitation

facilities in schools, especially

sex-specific toilets

Key recommendations for policymakers, NGOs, advocates, and donors
- Focus efforts in the places and stages where there are still gender gaps in enrollment and completion. Depending on location, this may be in primary completion, the transition to secondary, or secondary completion.

- In the context of COVID-19, additional efforts are needed to address issues of cost (through reducing fees, providing materials), food insecurity (through school feeding), accessibility (through safely opening schools, expanding access to remote learning as needed), and competing demands on girls' time (through incentives to get girls back to school, flexible school hours). 


\section{Programs that we know work when it comes to improving learning for both girls and boys:}
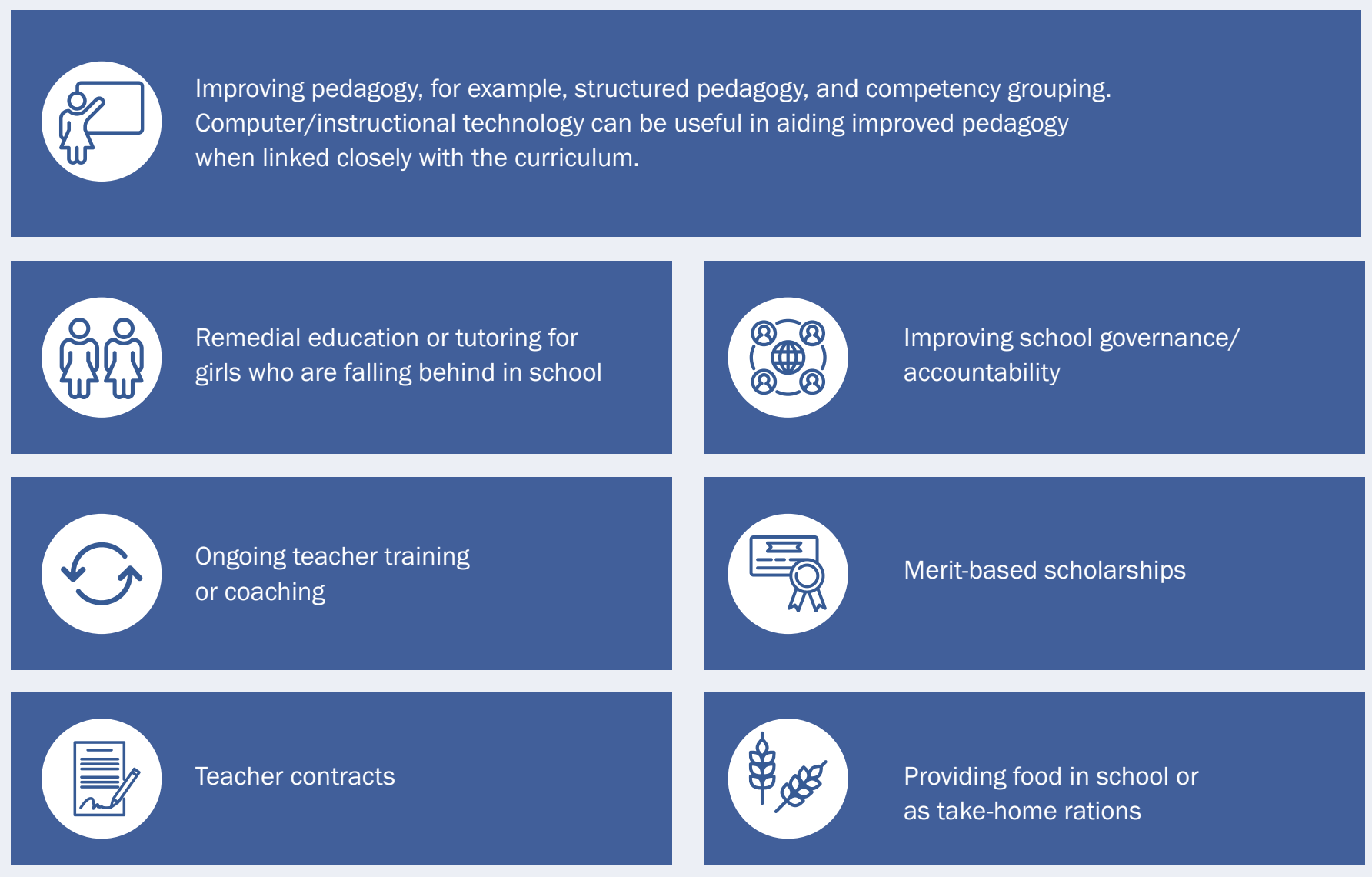

\section{Key recommendations} for policymakers, NGOS, advocates, and donors
- Shift resources to focus more on improving learning, which is a near universal challenge, often faced by both girls and boys. A core goal of every girls' education program should be to ensure that girls are literate.

- In the context of COVID-19, additional efforts are needed to support teachers in addressing new challenges to learning as children return to school, including skill loss (e.g., through competency grouping), and adapt effective pedagogical approaches to remote learning as needed.

\section{Here are ways to better integrate evidence into common approaches to improving girls' education:}

Plan trainings in gender-sensitive pedagogy

to include training on improved pedagogy,

and using competency grouping

Combine efforts focused on building reading skills (using improved pedagogy) with content integrating messages on gender, rights, and power
Explore opportunities to add food provision into existing efforts to make schooling more affordable, which could help narrow gender gaps while also supporting children from the poorest households

Partner with ongoing programs outside of the education space that focus on delaying marriage and childbearing and preventing violence against children and young people 


\section{Where to focus research efforts}

Prioritize evaluation of common interventions, often developed in response to perceived needs on the ground.

\section{Here are the most commonly used approaches in the girls' education field that have not yet been shown to improve education outcomes:}

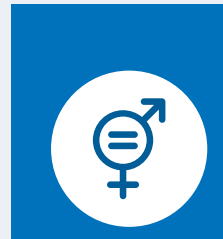

Life skills education, including content on gender, rights, and power, empowerment training, sexual and reproductive health education, and provision of safe spaces and social connections

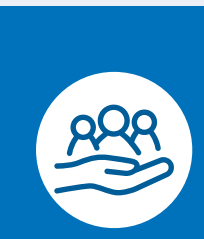

Community engagement and efforts to increase support for girls' education
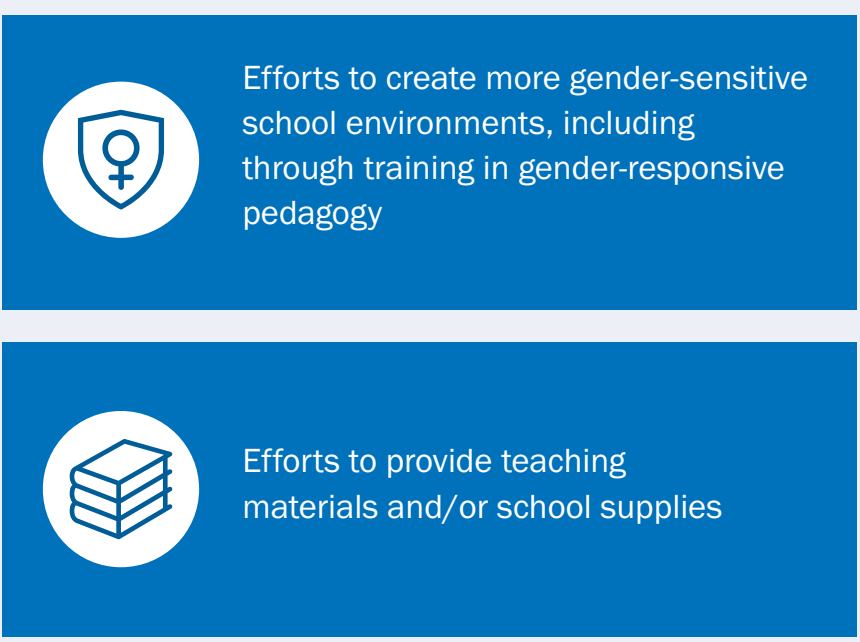

Key recommendations for policymakers, NGOs, advocates, and donors
- The most useful evaluations will be those that test multicomponent programs in a way that offers insights into which components, or combinations of components, are most effective and most cost-effective in which settings.

- More research is needed in the settings where girls' education needs are greatest, including parts of West Africa, South Asia, and settings affected by conflicts and crises.

- Adapt and extend evidence on what works to improve learning (e.g. improved pedagogy) to understand whether and how these approaches work best for girls. At a minimum, this means reporting results from evaluations for girls and boys separately.

- Develop a shared framework of gender-related barriers to education. Include clear definitions of barriers, data sources to track progress, and guidance on which approaches address each barrier most effectively. Develop easy-to-use tools to guide program and policy design based on a diagnosis of barriers in each setting. 


\section{Right now, how can the entire global girls' education community accelerate progress?}

SEEK OPPORTUNITIES TO COLLABORATE MORE CLOSELY, and more regularly, with organizations playing different roles in this field. As the work of all actors continues to evolve rapidly, such collaborations will help better align needs, evidence, and practice in global girls' education.

BY SHIFTING OUR APPROACH AS A FIELD-linking our paths more closely together rather than moving forward on our own-we can address gaps among needs, evidence, and practice and accelerate progress.
The Evidence for Gender and Education Resource, or EGER, offers a platform and resource for the global girls' education community to do just that. Visit EGER at egeresource.org and share your work.

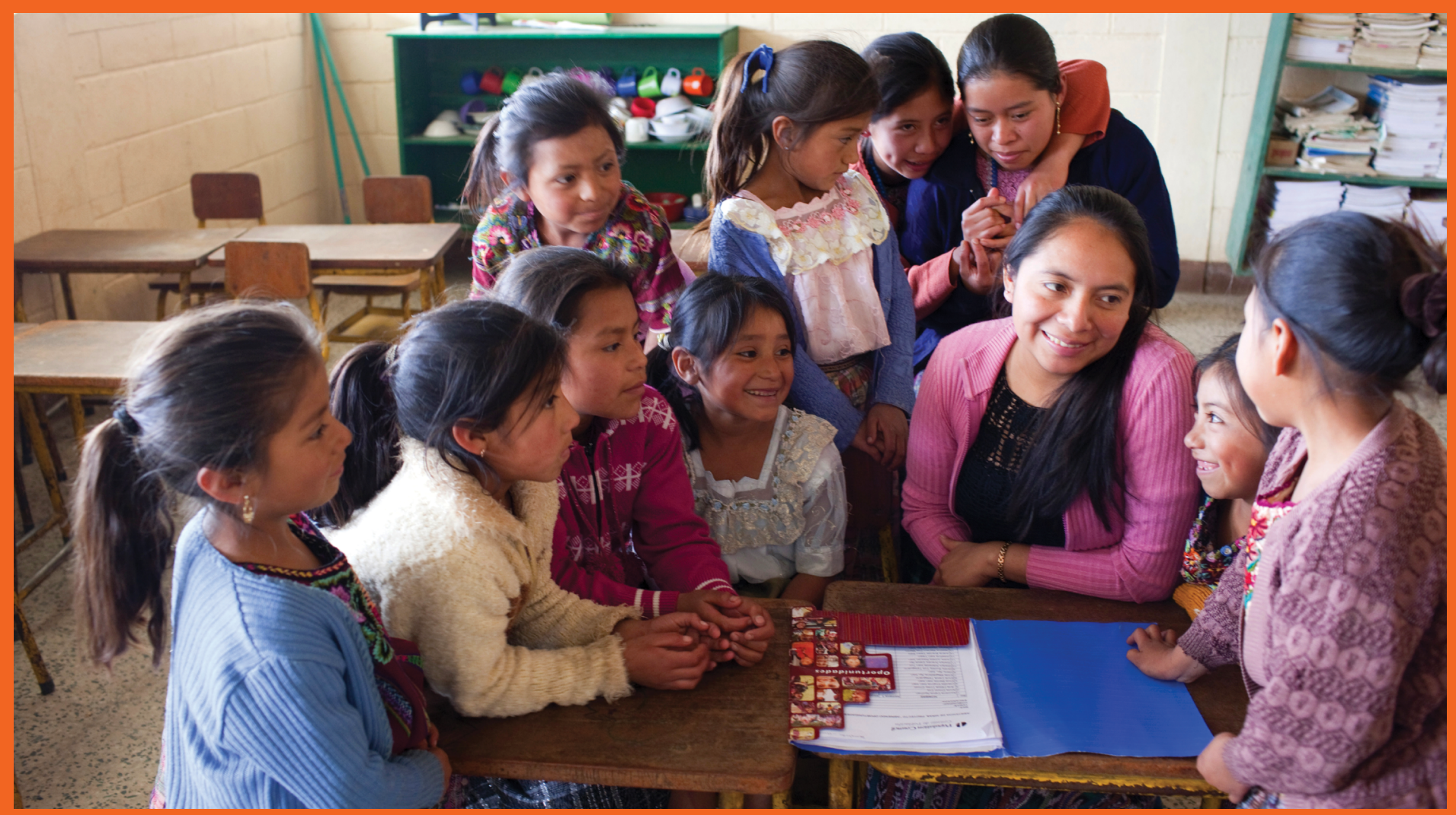


The Evidence for Gender and Education Resource (EGER) is the first freely available resource to help the global gender and education community make informed decisions about their programming, investments, and policy and research priorities. EGER is a searchable, easy-to-use, interactive database for practitioners, researchers, donors, and decisionmakers to drive better education results for girls, boys, and communities around the world.
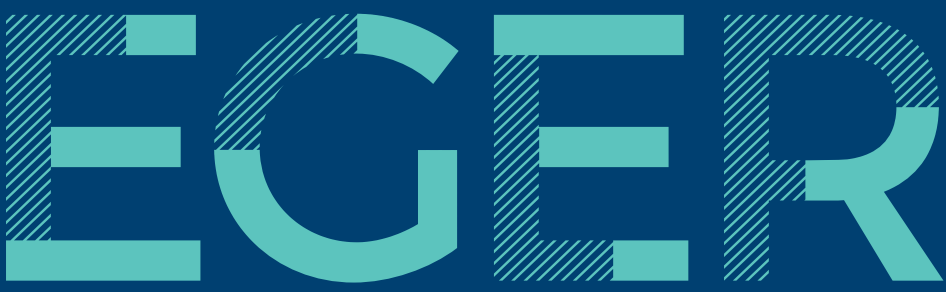

EVIDENCE FOR GENDER AND EDUCATION RESOURCE
For more information please visit:

\section{EGER}

egeresource.org

Echidna Giving

echidnagiving.org

Population Council's GIRL Center popcouncil.org/girlcenter

Suggested citation: Psaki, S., N. Haberland, M. Kozak, and

L. Woyczynski. 2021. “Girls' Education Roadmap: 2021 Report

Summary." EGER Reports. New York: Population Council. 